OPEN ACCESS

Edited by:

Christine Moissl-Eichinger, Medical University of Graz, Austria

Reviewed by:

Juris A. Grasis,

San Diego State University, USA

Pablo Rodrigo Hardoim,

University of Algarve, Portugal

*Correspondence:

Murali Gopal

mgcpcri@yahoo.co.in

Specialty section:

This article was submitted to

Microbial Symbioses,

a section of the journal

Frontiers in Microbiology

Received: 14 May 2016 Accepted: 24 November 2016 Published: 07 December 2016

Citation:

Gopal M and Gupta A (2016) Microbiome Selection Could Spur Next-Generation Plant Breeding Strategies. Front. Microbiol. 7:1971. doi: 10.3389/fmicb.2016.01971

\section{Microbiome Selection Could Spur Next-Generation Plant Breeding Strategies}

\author{
Murali Gopal* and Alka Gupta \\ Microbiology Section, ICAR-Central Plantation Crops Research Institute, Kasaragod, India
}

"No plant is an island too..."

Plants, though sessile, have developed a unique strategy to counter biotic and abiotic stresses by symbiotically co-evolving with microorganisms and tapping into their genome for this purpose. Soil is the bank of microbial diversity from which a plant selectively sources its microbiome to suit its needs. Besides soil, seeds, which carry the genetic blueprint of plants during trans-generational propagation, are home to diverse microbiota that acts as the principal source of microbial inoculum in crop cultivation. Overall, a plant is ensconced both on the outside and inside with a diverse assemblage of microbiota. Together, the plant genome and the genes of the microbiota that the plant harbors in different plant tissues, i.e., the 'plant microbiome,' form the holobiome which is now considered as unit of selection: 'the holobiont.' The 'plant microbiome' not only helps plants to remain fit but also offers critical genetic variability, hitherto, not employed in the breeding strategy by plant breeders, who traditionally have exploited the genetic variability of the host for developing high yielding or disease tolerant or drought resistant varieties. This fresh knowledge of the microbiome, particularly of the rhizosphere, offering genetic variability to plants, opens up new horizons for breeding that could usher in cultivation of next-generation crops depending less on inorganic inputs, resistant to insect pest and diseases and resilient to climatic perturbations. We surmise, from ever increasing evidences, that plants and their microbial symbionts need to be co-propagated as life-long partners in future strategies for plant breeding. In this perspective, we propose bottom-up approach to co-propagate the co-evolved, the plant along with the target microbiome, through - (i) reciprocal soil transplantation method, or (ii) artificial ecosystem selection method of synthetic microbiome inocula, or (iii) by exploration of microRNA transfer method - for realizing this next-generation plant breeding approach. Our aim, thus, is to bring closer the information accrued through the advanced nucleotide sequencing and bioinformatics in conjunction with conventional culture-dependent isolation method for practical application in plant breeding and overall agriculture.

Keywords: microbiome, holobiont, artificial ecosystem selection, plant breeding, synthetic microbiota 


\section{THE 'HOLOBIONT' AS HERITABLE UNIT OF SELECTION}

In the age of new ecology, the understanding of a plant as no more an individual at its genomic level but a larger genetic entity comprising of its associated microbial genome, 'the microbiome,' has given rise to the 'holobiont' concept (Zilber-Rosenberg and Rosenberg, 2008; Rosenberg and ZilberRosenberg, 2016). A 'holobiont' is thus an assemblage of the individual and its symbionts living and functioning as a unit of biological organization (Bordenstein and Theis, 2015; Theis et al., 2016), having the capacity to replicate and pass on its genetic composition; therefore, a unit of selection (ZilberRosenberg and Rosenberg, 2008; Booth, 2014; van Opstal and Bordenstein, 2015). The genomic reflection of complex symbiotic interactions of the plant holobiont is governed by its holobiome or hologenome comprising of the host and its microbial genome (Guerrero et al., 2013; Bordenstein and Theis, 2015). In fact, the collective genome of the rhizosphere microbiome is much larger than that of the plant and therefore referred to as the plant's second genome or pan-genome (Berendsen et al., 2012; Turner et al., 2013). The 'holobiont' concept has its roots in the hypothesis that the complex eukaryotic cells have evolved from simple prokaryotes (Embley and Martin, 2006; Douglas, 2014; Koonin and Yutin, 2014). The recent finding of 'Lokiarchaeota,' a complex archaeabacteria clade that appears to be a missing link between prokaryotes and eukaryotes (Spang et al., 2015), strengthens the presence of prokaryote-to-eukaryote genomic continuum in the plant holobiont (Turner et al., 2013).

\section{THE MICROBIOME REGULATES HOLOBIONT FITNESS}

The plant microbiome is compartmentalized into its rhizosphere, endosphere, phyllosphere, and endophytic microbiota (Figure 1) with soil largely being the original source of the microbial diversity as observed in Arabidopsis, maize, rice, grapevine, cannabis and cucurbits (Bulgarelli et al., 2012; Lundberg et al., 2012; Schlaeppi et al., 2014; Winston et al., 2014; Edwards et al., 2015; Glassner et al., 2015; Zarraonaindia et al., 2015). It has also been reported that the diversity of above ground phyllosphere microbiota includes many taxa that are encountered in soil and water (Vorholt, 2012; Kembel et al., 2014). The selection of the microbes from the soil pool into the plant microbiome is driven by the host (Berg and Smalla, 2009; Hartmann et al., 2009; Hirsch and Mauchline, 2012), modulated by salicylic acid production (Lebeis et al., 2015) as well as phenols (Badri et al., 2013a) released from the roots, and the plant's evolutionary history (Bouffaud et al., 2014). In the ecological perspective, the plant holobiont and not the plant as an individual, is now known to respond to the various biotic and abiotic perturbations in a given environment. A significant proportion of the plant holobiont's response is contributed by the microbial symbionts via their ecological services of nutrient mineralization and delivery (Terrazas et al., 2016), protection from pests and diseases, and tolerance to abiotic stress. Therefore, the overall fitness of the plant is governed by the self and its microbiota (Vandenkoornhuyse et al., 2015). Several examples where the plant microbiome, particularly of the root and endophytic compartments, has been used to suppress diseases of field and horticultural crops (Mendes et al., 2011; Spence et al., 2014; Cha et al., 2016), improve drought resistance in desert crops (Lau and Lennon, 2012; Marasco et al., 2012) and grapevine (Rolli et al., 2015) and alter above-ground herbivory (Hol et al., 2010; Badri et al., 2013b) have unequivocally proved that the host microbiome indeed impact the fitness of the plants. Next-generation sequencing technologies, advanced bioinformatic analyses coupled with meticulous culture-dependent isolations had been employed in all the above studies to decode the plant microbiome and get to the important bacterial species involved in regulating the phenotypic expression of the plants.

\section{MICROBES WORK IN NETWORK MODE TO REGULATE PLANT FITNESS}

A 'microbiome' includes bacteria, fungi, actinomycetes, viruses, and protists. However, current information pertaining to the plant microbiome is mostly in reference to the bacterial community. Fungal and virus microbiome research have just begun. Several exciting new studies are unveiling the way in which the plant microbiome performs its duties. They indicate that, like any other species, microorganisms - operate in interlocked networks (van der Heijden and Hartmann, 2016) possessing microbial hubs. Within the networks reside certain keystone species that are critical for the plant-microbe interactions (Agler et al., 2016). It has been found that bacterial communities having high connectence and low nestedness afford them a stabilizing configuration which are able to prevent pathogen attack on some plants (Wei et al., 2015). Before these basic findings became apparent, several works clearly indicated more efficiency when bacteria were applied in a consortium mode for controlling soil borne pathogens (Stockwell et al., 2011; Sarma et al., 2015). Mendes et al. (2011) reported that control of Rhizoctonia solani of sugar beet in disease suppressive soil was because of a suite of 111 Pseudomonas spp. representing the bulk of antagonistic bacteria isolated from the soil, confirming the results obtained by metagenomic analysis of the disease suppressive soil. Similarly, the work of Koberl et al. (2013) in managing Ralstonia disease in medicinal crops in arid ecosystem of Egypt, using a combination of 45 Bacillus spp. with Streptomyces, highlight the phenomenon that microbes act in network mode. A core consortium of five bacteria was found to rescue tobacco (Nicotiana attenuate) from the sudden-wilt caused by Fusarium-Alternaria like complex in continuous cropping system (Santhanam et al., 2015). Consortia level application had also helped in improving drought tolerance in grape vine (Rolli et al., 2015) and date palm (Cherif et al., 2015). A combination of Pseudomonas spp. altered the post-embryonic root development in Arabidopsis that stimulated production of more lateral roots and root hairs and helped the plants perform better under waterand nutrient-limited conditions (Zamioudis et al., 2013). These results indicate that there is better performance of bacteria when 




FIGURE 1 | The 'Plant Microbiome' can be described as the sum total of the genomic contribution made by the diverse microbial communities that inhabit the surface and internal tissues of the plant parts. The rhizosphere, endosphere, phyllosphere constitute the major compartments in which the microbial communities reside in the plant. The soil microbiome is the main source from which the plant selects and builds its microbiome profile. The plant genotype (e.g., dicot bean plant and a monocot rice plant), its root exudates (indicated by blue shade for bean and green for rice), the soil types and properties, and the environmental factors influence the plant microbiome makeup (indicated by different colored microbes inhabiting the plant compartments in bean and rice plant). Mycorrhizal association in both plants is indicated by thin lines extending from the roots into the surrounding soil.

they are applied in a consortium underlining their network mode of activity (Hays et al., 2015) in regulating plant fitness. Now, the plant-microbiome relationship via 'holobiont' concept is not only restricted to production and protection applications in plants but is also expanding into the realm of plant breeding.

\section{CONVENTIONAL SELECTION BREEDING FOCUSED ON PLANT GENOME}

Wild plants have evolved over time by selectively assembling plant-beneficial microbiota from soil as their partners. This association was disrupted with the development of agriculture through domestication of important crops. Further disruption entailed as conventional plant breeding and modern genomicsassisted methods focused only on the plant genome, not the hologenome, for developing crops with higher yield, resistance to insect pest and fungal pathogens, tolerance to abiotic stresses such as drought and salinity and characteristics of superior quality for many other desirable attributes. Plant breeding has greatly helped in the food security of the global population. However, domestication of such genetically homogenous crops, cultivated in different ecological conditions, has led to not only the erosion of genetic diversity of the plants; but also extinction of huge microbial diversity in soil that would have been the source of several plant-beneficial microbiota (Perez-Jaramillo et al., 2016).

Domestication and intensive cultivation of a single crop has led to appearance of several qualitative issues such as reduced nutrient use efficiency, increased susceptibility to pests and diseases, inability to overcome abiotic stresses, etc. Domestication also could have removed those traits from plants that were needed to assemble host-specific microbiome affording the plants a very high adaptability to biotic and abiotic stresses (Bulgarelli et al., 2013; Chen et al., 2015). This necessitated application of high quantities of inorganic fertilizer, spraying of insecticides and growth hormones, etc. to maintain the required output (Matson et al., 1997) and on the flip side, drastically losing the soil microbial diversity to a great extent (Weese et al., 2015). Integration of plant-beneficial microorganisms such as nitrogenfixing bacteria, phosphate solubilizing microbes, plant growth promoting rhizobacteria (PGPR) and arbuscular mycorrhizae were included as agronomic components of crop husbandry and became an environmentally benign alternative to supplement the inorganic inputs. From individual inoculations in the beginning, either bacteria or fungi, to mixed inoculations having both bacteria and fungi yielded desirable results in some crops grown under certain soil and environmental conditions. However, the microbial applications did not always perform to expected levels 
under different ecological conditions even if the host was the same (Ambrosini et al., 2016). Perhaps singular or combination of two microbes were not able to establish in the soil resulting in below par effectiveness of the bioinoculants. One of the possible reasons could be that the introduced microbes were not able to find their interdependent groups in the foreign soil as in the native soils from which they were originally isolated, which would have helped them to share and exchange critical metabolites like amino acids and sugars to promote their survival under challenging microenvironments. In short, microorganisms are dependent upon their groups for key metabolites to cooccur in an environment having diverse microbial communities (Zelezniak et al., 2015). This again highlights the fact that microorganisms work in network mode and their networking offers a broad base of microbial genomic diversity that could impact plant genetic variability.

\section{MICROBIOME OFFERS GENETIC VARIABILITY TO PLANTS}

Genetic variability in plants, in the form of landraces and wild relatives, is a key factor that conventional plant breeders focused on to produce new varieties and hybrids. This approach, as mentioned earlier, completely focused on the plant genome for the variability. Though, it has yielded splendid results in developing better crops in terms of yield, selection and domestication has led to erosion of plant genetic diversity making plant breeders look for newer sources of variability in plants. With advancement in cutting edge technologies, another new source of variability in plant genetic material viz. 'epigenetics', has become a focus in crop improvement programs in recent years (Varshney et al., 2005; Tsaftaris et al., 2008). Epigenetics refers to the different phenotypic manifestations by plants arising from altered expression of genes without any actual changes in the base pairs. Mechanisms driving epigenesis include: DNA methylation, modifications in chromatin via modifications in the histones and DNA, and RNA interference. It is considered heritable too. Epigenetics pathways are, therefore, reported to produce phenotypic plasticity in plants which enables them to overcome and reproduce in erratic ecosystems (Pikaard and Scheid, 2014). A report on the recently concluded meeting of Epigenetics of Plants International Consortium in the USA highlighted several themes including basic mechanisms of gene regulation, nucleolar dominance, histone dynamics, DNA methylation, and small RNA functions in plant epigenetics and how they could be used for crop improvement as well as stress and defense response by plants (Slotkin, 2016).

Apart from these, the development of holobiont theory is now unveiling a new basis of genetic variation, which is heritable and offered by the plant microbiome, particularly from the endophytic compartment (Nogales et al., 2016). The dependence of plant on its microbiome is to such a great extent that many plants failed to be cultured as transplants in the absence of bacterial and fungal endophytes (Hardoim et al., 2008). Among the endophytes, seed endophytes are of great importance because seeds not only carry the genetic blueprint of plants during transgenerational propagation, but are home to diverse microbiota too. Advancements in the knowledge of microbiome associated with seeds has, therefore, become critical as it forms the basis of vertical transmission of the microorganisms and hence, acts as a closely linked reservoir of plant endophytic microbiome having many positive impacts on plant germination and growth (Hardoim et al., 2015; Truyens et al., 2015). The transmission of endophytic bacteria can take place from parent plant to seed and then to the seedlings (proper vertical transmission), as in rice, or as in wheat, where bacteria are present in the seed coat, crease tissue and endosperm (Robinson et al., 2016). Studies performed to track the seed microbiome diversity indicated that a core-microbiota of endophytes was conserved during the domestication of wild maize (teosinte) to 10 different varieties of modern cultivated maize (Johnston-Monje and Raizada, 2011). In rice too, about $45 \%$ of the bacterial endophytes present in first seed generation were found to be transmitted to the second generation, in a study carried out using PCR-DGGE method with surface sterilized seeds (Hardoim et al., 2012). Bacterial endophytes, such as Bacillus spp. transmitted vertically in quinoa, helped in priming of the seeds to counter external reactive oxygen species during germination, thereby, helping the plants to overcome saline and dry soil pressures and improve their stress resistance (Pitzschke, 2016). While terroir was considered as the main source of seed microbial communities (Klaedtke et al., 2015), it was observed that a flux also existed between the rhizosphere and seeds with regard to endophytes. JohnstonMonje and Raizada (2011) have reported such a flux where a seed bacterium, Enterobacter asburiae, was found to egress out of the root and colonize the maize rhizosphere, thereby, indicating that seeds can also modulate the rhizosphere microbiome (JohnstonMonje et al., 2016). Thus, in plants like maize, seeds are known to propagate a set of core-microbiome from generation to generation even when grown in ecologically different soil conditions (Johnston-Monje et al., 2014). Seed microbiome, therefore, form an important source of variability in plants.

Next to seeds, the rhizosphere microbiome introduces heterogeneity in plants by affecting their health and productivity (Berendsen et al., 2012; Berg et al., 2014; Pieterse et al., 2016), improving stress tolerance (Rodriguez et al., 2008), and providing an overall adaptive advantage (Haney et al., 2015). The works of Lau and Lennon (2011, 2012), Panke-Buisse et al. (2014), and Wagner et al. (2014) bring to light the role of soil or rhizosphere microbiome in altering the flowering time, indicating the depth of variability microbiomes offer to plant genome. Microbiomes that help plants develop early or late flowering could be used as breeding strategies to escape drought or salinity or heat or cold stress as plants are known to adopt altered flowering time in response to the above abiotic stresses (Kazan and Lyons, 2016). Therefore, sufficient evidence has accrued to show that the microbiome mediates several critical plant functional traits (Friesen et al., 2011), has a great significance on plant phenotypic plasticity (Goh et al., 2013), and can become a new trajectory for plant neodomestication (Duhamel and Vandenkoornhuyse, 2013). In addition to the variability proffered to plants by the microbiome diversity harbored in various plant tissues, another 
layer of variability is also added by the epigenetic occurrences in the microbiome similar to epigenetic occurrences in plants. DNA methylation in bacteria and archaebacteria not only saves their DNA from self cleavage by its restriction enzymes through restriction modification but is also involved in gene regulation and introduces genetic variability (Casadesus and Low, 2006). Studies using the single molecule real-time (SMRT) sequencing technology in 230 bacterial and archaeal species showed pervasive occurrence of DNA methylation in 93\% of the observed species, stressing the incidence of epigenetic events in prokaryotes. The study unraveled twice as many hitherto known DNA binding specificities of methytransferases (MTases) and more than 800 distinct reproducible methylated motifs (Blow et al., 2016). The role of epigenetic events becomes more relevant to our perspective when it is reported to drive the phase change of freeliving bacteria such as Bradyrhizobium diazoefficiens to symbiotic bacteria because of methylation of specific motifs during the process of symbiosis (Davis-Richardson et al., 2016). Yet another basis of variability in the microbiome is the phenomenon termed as 'horizontal gene transfer' (HGT) (de la Cruz and Davies, 2000) that predominantly occurs in rhizosphere environment. This becomes an additional derivative for heterogeneity to the plants. HGT is brought about by the mobile elements such as gene cassettes, plasmids, transposons, and bacteriophages. Thus, it is evident that the microbiome is able to offer important genetic variability to plants that can be considered for future plant breeding strategies, particularly, when an experimental technique such as artificial ecosystem selection is now available to transfer the complete microbial community.

\section{ARTIFICIAL ECOSYSTEM SELECTION OF PLANT MICROBIOME}

Application of individual microorganism (bacteria or fungi) for improving plant growth, health and overall fitness is comparatively an easy task. But its success in an open system is challenging. Whereas, the application at the microbiome or core-microbiome level has shown to be more successful for the reasons explained elsewhere. However, getting to the relevant bacterial species and preparing their appropriate consortia is the main challenge here because of the complex nature of the microbe-plant interactions. By adopting artificial ecosystem selection method of microbiome transfer (Swenson et al., 2000; De Roy et al., 2014; Voss et al., 2015), strong evidence of heritable changes in drought tolerance in Arabidopsis thaliana (Zolla et al., 2013), alteration of flowering time in Arabidopsis thaliana genotypes, Brassica rapa (Panke-Buisse et al., 2014) and Boechera stricta (Wagner et al., 2014) have been reported. The findings of overlapping core-microbiome in sugarcane (Yeoh et al., 2015) and rice (Edwards et al., 2015) with those of Arabidopsis (Lundberg et al., 2012) give more hope for cross-compatibility of microbiome transfer with phylogenetically unrelated plant species. Not only bacterial but fungal communities are also shared between different plant compartments, with soil being the main source (Coleman-Derr et al., 2016). Even the important biocontrol fungus Trichoderma has been found to have a global core community in endemic plants such as Aeonium, Diospyros, Hebe, Rhododendron in comparison with cosmopolitan plants like maize (Zachow et al., 2016).

Interestingly, this new area of synthetic ecology, in which ecologists and medical professionals design beneficial microbial communities, has its origins in almost century-old field ecological studies (Inouye, 2015), such as the one carried out by Henry (1931), wherein control of Helminthosporium foot rot disease of wheat was achieved by transplantation of soils suppressive to the pathogen. More recently, using a similar soil inoculation technique, it has been shown that plant communities can be restored quickly on degraded or disturbed land with soil communities such as microbes, nematodes and microarthropods being some of the main drivers (Wubs et al., 2016).

\section{HOST GENOME AND ITS MICROBIOME: STRANGE, THEY ARE NOT BED FELLOWS YET IN THE STRATEGY FOR PLANT BREEDING}

As an integral part of the plant hologenome, the plant microbiome is a tool that can be selected together with the plant genome to develop next-generation plant breeding approach. Though some critical views on studies of the microbiome (Hanage, 2014) and hologenome concept (Moran and Sloan, 2015; Douglas and Werren, 2016) exist, it is possible to develop a new plant breeding strategy in which the plant microbiome from a desired field can be developed into a synthetic inoculum and reared with the plant progeny to produce nextgeneration crops. Challenges for developing large quantities of the microbiome inoculum can be surmounted with the help of next-generation sequencing technologies combined with bioinformatic analyses for determining the pan-microbiome, at different hierarchical scales, on which the plant depends for its fitness (Vandenkoornhuyse et al., 2015) and identifying candidate organisms whose abundance in soil correlates with the plant function (Wagner et al., 2014). Systematic isolations that capture the species present in a community (Bai et al., 2015) which produce the desired phenotypic effect will be able to help kick-start this effort. The proposed new plant breeding strategy is an extension of the bespoke microbiome therapy where the possibility of transfer of core-microbiome from pathogen suppressive soils to pathogen prevalent soils was suggested for managing plant diseases (Gopal et al., 2013). It also draws upon from the 'neodomestication' of plants along with its full complement of mutualist theme put forth by Sessitsch and Mitter (2015) as the concept for current century's agriculture for attaining food security. Berg et al. (2016) advocated integration of plant-associated microbiome in research dealing with plant physiological experiments and breeding approaches for the reason that plant microbiome is known to respond ahead of its host plant to any environmental perturbation, which influences the hormonal activity of the plant and thereby its physiology. This integration would lead to 

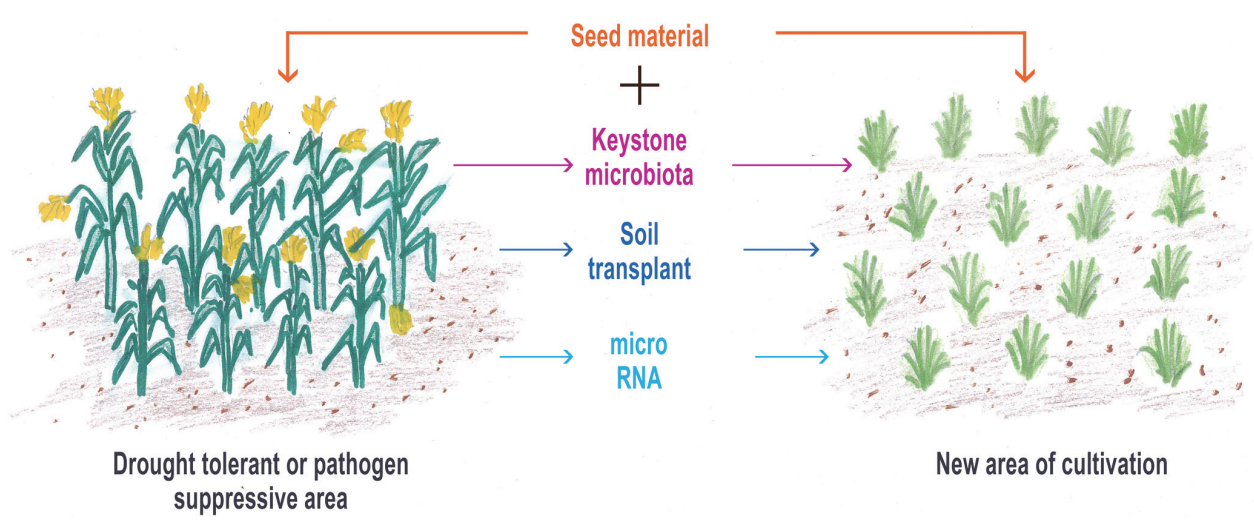

New area of cultivation

FIGURE 2 | This represents the direct (keystone microbiota and soil transplant) and the indirect methods (microRNA transfer) of co-propagating the microbiome with planting material from selected situations for raising next-generation crops.

improved understanding of the plant-microbiome interactions and would help in unraveling the functions of the holobiont. They considered it necessary to include cultivar-specific microbiomes in plant breeding studies in view of the high-specificity observed between the symbionts and its host, thus, providing relevant inputs to our proposed perspective on use of microbiome for plant breeding. In another elaborate report, Mueller and Sachs (2015) professed a top-down approach for artificially selecting upon plant and animal microbiomes for improving their health. They described co-evolution as an evolutionary adjustment occurring between two interdependent populations of species in such a way that changes in one population brings about reciprocal changes in the other, and co-propagation as the continuous transmission of host and its microbiome across several generations linking them together in each round of replication. The approaches envisaged by them to establish the functions of microbiome, techniques to manipulate the microbiome through host-mediated selection and to develop starter microbiome culture also form basis of our bottom-up perspective of co-propagating the co-evolved.

\section{CO-PROPAGATING THE CO-EVOLVED}

The approach in our proposed perspective is to co-propagate the co-evolved, i.e., the plant genome and its microbiome. It aims to propel the development in the current knowledge of the microbiome to more practical use in plant breeding, particularly in consideration of disease and drought management, two areas in urgent need of attention to improve agricultural production for food security (Lakshmanan et al., 2014; Haney et al., 2015) in the climate change scenario (Hamilton et al., 2016). Drought and extreme heat, in particular, have been the reason for up to $10 \%$ decline in yield of cereals around the world making it the top challenge to crop production (Lesky et al., 2016). Scope for tackling drought using PGPR, i.e., rhizosphere microbiome, is a good option (Ngumbi and Kloepper, 2016). With the current knowledge on the plant microbiome, which is mainly concentrated on bacterial communities, we suggest to co-propagate the microbiome with the plant offspring in the new cultivation with a starter microbiome culture of keystone plant-beneficial microbiota from the target soils. This approach will provide an opportunity to the plants to easily recognize the suite of microbiota with which it had co-evolved and, therefore, preferably recruit them in the new environment. It is also possible that the offspring may have a set of microbiota transferred vertically from the parent, which will enable them to function efficiently in the new environment, if their microbiota are able to interact with the known set of rhizosphere microbiome that was available in the original soil environment in which the parents of the offspring grew. It is now known that the roots attract 2-10 times more types of bacteria than leaves and that the root microbiome is regulated by soil factors such as $\mathrm{pH}$, moisture, and temperature in addition to plant genotype and age (Wagner et al., 2016). Our strategy, therefore, tries to provide the missing microbiome as starter rhizosphere microbiome culture that the plant may require to perform in new environments (Figure 2). Providing the starter microbiome culture can be attained either by direct approaches of (i) reciprocal soil transplantation/inoculation from the original soil in which the desired plant had been grown, and (ii) development of synthetic microbiome containing keystone microbiota (plantbeneficial bacteria, arbuscular mycorrhizae, and actinomycetes) or by indirect approach of (iii) transferring microRNA from rhizosphere of target soils to recipient soils. Experiments showing reciprocal soil inoculation or soil transplantation capable of surmounting disease in wheat (Henry, 1931), restore degraded land and giving direction to the type of vegetation grown based on soil inocula (Wubs et al., 2016) and degrade crude oil (Bell et al., 2016) lend credence to the first approach. The work of Calderon et al. (2016) on the restoration of the microbial communities responsible for $\mathrm{N}$-cycling in degraded soil using reciprocal soil inoculum suggests that having an understanding of the priority effects along with the relatedness of the established microbial community and the introduced microbial communities could help in better microbial assemblage and successful restoration of target areas. In a recent work of Bai et al. (2015), it has been shown that, with some meticulous, 
systematic and exhaustive isolation of bacteria from phyllosphere and rhizosphere, it is possible to capture majority of the species found reproducibly in their respective natural communities. Studies with synthetic communities of bacteria prepared from the isolations could replicate the gnotobiotic reconstitution system allowing for bacterial community establishment. Current research approach for isolation of 'unculturable' microbiota from the human gut using cutting edge genomics and bioinformatics tools (Browne et al., 2016) can be followed to isolate keystone microbiota from target soils. More support to the second strategy comes from the work of Panke-Buisse et al. (2016) wherein inoculation of a subset of whole microbiome, associated with early flowering in Arabidopsis thaliana cultivated on four different types of solid media, was able to reproduce the same flowering timing in Arabidopsis. The third strategy mentioned using transfer of rhizosphere microRNA is a possibility of adopting the recent development in human gut microbiology where it has been shown that incorporation of microRNAs harvested from feces is able to restore the disturbed gut microbiome to healthy status (Liu et al., 2016). One recent report by Zhang et al. (2016) highlighting export of microRNAs (miRNA166 and miRNA 159), accumulated in root-hypocotyl junction, cotyledon vasculatures, root tissues, etc. of cotton plants, to the hyphae of pathogenic fungus Verticillium dahliae to suppress its virulence, suggests that the third strategy is also feasible.

The ultimate aim of the perspective is to take the research out of the lab and apply it to practical farming techniques using a matching microbiome inoculum to cultivate a given crop. Our perspective reflects the opinion of Denison (2014) who suggested that the key to past and future agriculture depended on increasing the cooperation among plants, their symbionts and the farmers. To make this happen, awareness

\section{REFERENCES}

Agler, T. A., Ruhe, J., Kroll, S., Morhenn, C., Kim, S. T., Weigel, D., et al. (2016). Microbial hub taxa link host and abiotic factors to plant microbiome variation. PLoS Biol. 14:e1002352. doi: 10.1371/journal.pbio. 1002352

Ambrosini, A., de Souza, R., and Passaglia, L. M. P. (2016). Ecological role of bacterial inoculants and their potential impact on soil microbial diversity. Plant Soil 400, 193-207. doi: 10.1007/s11104-015-2727-7

Badri, D. V., Chaparro, J. M., Zhang, R., Shen, Q., and Vivanco, J. M. (2013a). Application of natural blends of phytochemicals derived from the root exudates of Arabidopsis to the soil reveal that phenolic-related compounds predominantly modulate the soil microbiome. J. Biol. Chem. 288, 4502-4512. doi: 10.1074/jbc.A112.433300

Badri, D. V., Zolla, G., Bakker, M. G., Manter, D. K., and Vivanco, J. M. (2013b). Potential impact of soil microbiomes on the leaf metabolome and on herbivore feeding behavior. New Phytol. 198, 264-273. doi: 10.1111/nph. 12124

Bai, Y., Muller, D. B., Srinivas, G., Garrido-Otter, R., Potthoff, E., Rott, M., et al. (2015). Functional overlap of the Arabidopsis leaf and root microbiota. Nature 528, 364-369. doi: 10.1038/nature 16192

Bell, T. H., Stefani, F. O. P., Abram, K., Champagne, J., Yergeau, E., Hijri, M., et al. (2016). A diverse soil microbiome degrades more crude oil than specialized bacterial assemblages obtained in culture. Appl. Environ. Mocrobiol. 82, 55305541. doi: 10.1128/AEM.01327.16 amongst farmers about the beneficial role of microorganisms in plant production and protection will need to be strengthened through innovative extension programs and communications (Shugart and Racaniello, 2015). Mass-production of the starter microbiome inoculum can be thought of with improvements in the additive printing technology (3D printing technology) of microscopic bacterial communities (Connell et al., 2013). Though the plant microbiome research is in its growing stage, with increased understanding of the mechanisms by which community coalescence takes place vis-a-vis the microbial assemblage (Rillig et al., 2016) and several new methods available for studying the rhizosphere environment (Oburger and Schmidt, 2016) including nano-scale tools (Biteen et al., 2016), the challenge can be surmounted with improvement in the knowledge of the microbe-to-microbe and microbe-to-plant interactions by the end of the decade (Mitter et al., 2016) to be able to provide solutions for 21st century crises (Blaser et al., 2016).

\section{AUTHOR CONTRIBUTIONS}

MG has originally thought about this concept. MG and AG have written the manuscript.

\section{ACKNOWLEDGMENTS}

The authors are extremely grateful to the reviewers for several rounds of reviewing and suggesting critical changes to improve the manuscript. The graphical representations were hand drawn by $A G$ and then photoshopped by Mr. C. H. Amarnath, Technical Officer (Retd.), for which authors express their sincere gratitude.

Berendsen, R. L., Pieterse, C. M. J., and Bakker, P. A. H. M. (2012). The rhizosphere microbiome and plant health. Trends Plant Sci. 17, 478-486. doi: 10.1016/j. tplants.2012.04.001

Berg, G., Grube, M., Schloter, M., and Smalla, K. (2014). Unraveling the plant microbiome: looking back and future perspectives. Front. Microbiol. 5:148. doi: $10.3389 /$ fmicb. 2014.00148

Berg, G., Rybakova, D., Grube, M., and Koberl, M. (2016). The plant microbiome explored:implications for experimental botany. J. Exp. Bot. 67, 995-1002.

Berg, G., and Smalla, K. (2009). Plant species and soil type cooperatively shape the structure and function of microbial communities in the rhizosphere. FEMS Microbiol. Ecol. 68, 1-13. doi: 10.1111/j.1574-6941.2009.00654.x

Biteen, J. S., Blainey, P. C., Cardon, Z. G., Chun, M., Church, G. M., Dorrestein, P. C., et al. (2016). Tools for the microbiome: nano and beyond. ACS Nano 10, 6-37. doi: 10.1021/acsnano.5b07826

Blaser, M. J., Cardon, Z. G., Cho, M. K., Dangl, J. L., Donohue, T. J., Green, J. L., et al. (2016). Toward a predictive understanding of Earth's microbiomes to address 21st century challenges. mBio 7:e00714-16. doi: 10.1128/mBio.00714- 16

Blow, M. J., Clark, T. A., Daum, C. G., Deutschbauer, A. M., Fomenkov, A., Fries, R., et al. (2016). The epigenomic landscape of prokaryotes. PLoS Genet. 12:e1006064. doi: 10.1371/journal.pgen.1006064

Booth, A. (2014). Symbiosis, selection and individuality. Biol. Philos. 29, 657-673. doi: 10.1007/s10539-014-9449-8

Bordenstein, S. R., and Theis, K. R. (2015). Host biology in the light of the microbiome: ten principles of holobionts and hologenomes. PLoS Biol. 13:e1002226. doi: 10.1371/journal.pbio.1002226 
Bouffaud, M.-L., Poirier, M.-A., Mulle, D., and Moenne-Loccoz, Y. (2014). Root microbiome relates to plant host evolution in maize and other Poaceae. Environ. Microbiol. 16, 2804-2814. doi: 10.1111/1462-2920.12442

Browne, H. P., Forester, S. C., Anonye, B. O., Kumar, N., Neville, B. A., Stares, M. D., et al. (2016). Culturing of 'unculturable' human microbiota reveals novel taxa and extensive sporulation. Nature 533, 543-547. doi: 10.1038/nature17645

Bulgarelli, D., Rott, M., Schlaeppi, K., Ver Loren van Themaat, E., Ahmadinejad, N., Assenza, F., et al. (2012). Revealing structure and assembly cues for Arabidopsis root-inhabiting bacterial microbiota. Nature 488, 91-95. doi: 10.1038/nature11336

Bulgarelli, D., Schlaeppi, K., Spaepen, S., Loren Ver van Themaat, E., and SchulzeLefert, P. (2013). Structure and functions of the bacterial microbiota of plants. Ann. Rev. Plant Biol. 64, 807-838. doi: 10.1146/annurev-arplant-050312120106

Calderon, K., Spor, A., Breuil, M.-C., Bru, D., Bizouard, F., Violle, C., et al. (2016). Effectiveness of ecological rescue for altered soil microbial communities and functions. ISME J. doi: 10.1038/ismej.2016.86 [Epub ahead of print].

Casadesus, J., and Low, D. (2006). Epigenetic gene regulation in the bacterial world. Microbiol. Mol. Biol. Rev. 70, 830-856. doi: 10.1128/mmbr.02016-06

Cha, J.-Y., Han, S., Hong, H.-J., Cho, H., Kim, D., Kwon, Y., et al. (2016). Microbial and biochemical basis of Fusarium wilt-suppressive soil. ISME J. 10, 119-129. doi: 10.1038/ismej.2015.95

Chen, Y. H., Gols, R., and Benrey, B. (2015). Crop domestication and its impact on naturally selected trophic interactions. Ann. Rev. Entomol. 60, 35-58. doi: 10.1146/annurev-ento-010814-020601

Cherif, H., Marasco, R., Rolli, E., Ferjani, R., Fusi, M., Soussi, A., et al. (2015). Oasis desert farming selects environment-specific date palm root endophytic communities and cultivable bacteria that promote resistance to drought. Environ. Microbiol. Rep. 7, 668-678. doi: 10.1111/1758-2229.12304

Coleman-Derr, D., Desgarennes, D., Fonseca-Garcia, C., Gross, S., Clingenpeel, S., Woyke, T., et al. (2016). Plant compartment and biogeography affect microbiome composition in cultivated and native Agave species. New Phytol. 209, 798-811. doi: 10.1111/nph.13697

Connell, J. L., Ritschdoff, E. T., Whiteley, M., and Shear, J. B. (2013). 3D printing of microscopic bacterial communities. Proc. Natl. Acad. Sci. U.S.A. 110, 1838018385. doi: 10.1073/pnas. 1309729110

Davis-Richardson, A. G., Russell, J. T., Dias, R., McKinlay, A. J., Canepa, R., Fagen, J. R., et al. (2016). Integrating DNA methylation and gene expression data in the development of the soybean-Bradyrhizobium N2-fixing symbiosis. Front. Microbiol. 7:518. doi: 10.3389/fmicb.2016.00518

de la Cruz, F., and Davies, J. (2000). Horizontal gene transfer and the origin of species: lessons from bacteria. Trends Microbiol. 8, 128-133. doi: 10.1016/ S0966-842X(00)01703-0

De Roy, K., Marzorati, M., Van den Abbeele, P., Van de Wiele, T., and Boon, N. (2014). Synthetic microbial ecosystems: an exciting tool to understand and apply microbial communities. Environ. Microbiol. 16, 1472-1481. doi: 10.1111/ 1462-2920.12343

Denison, R. F. (2014). Increasing cooperation among plants, symbionts, and farmers is key to past and future progress in agriculture. J. Bioecon. 16, 223-238. doi: 10.1007/s10818-014-9179-7

Douglas, A. E. (2014). Symbiosis as a general principle in eukaryotic evolution. Cold Spring Harb. Perspect. Biol. 6:a016113. doi: 10.1001/cshperspect. a016113

Douglas, A. E., and Werren, J. H. (2016). Holes in the hologenome: why hostmicrobe symbioses are not holobionts. mBio 7:e02099. doi: 10.1128/mBio. 02099- 15

Duhamel, M., and Vandenkoornhuyse, P. (2013). Sustainable agriculture: possible trajectories from mutualistic symbiosis and plant neodomestication. Trends Plant Sci. 18, 597-600. doi: 10.1016/j.tplants.2013.08.010

Edwards, J., Johnson, C., Santos-Medellin, C., Lurie, E., Podishetty, N. K., Bhatnagar, S., et al. (2015). Structure, varation, and assemble of root-associated micrbiomes of rice. Proc. Natl. Acad. Sci. U.S.A. 112, E911-E920. doi: 10.1073/ pnas. 1414592112

Embley, T. M., and Martin, W. (2006). Eukaryotic evolution, changes and challenges. Nature 440, 623-630. doi: 10.1038/nature04546

Friesen, M. L., Porter, S. S., Stark, S. C., von Wettberg, E. J., Sachs, J. L., MartinezRomero, E., et al. (2011). Microbially mediated plant functional traits. Annu. Rev. Ecol. Evol. Syst. 42, 23-46. doi: 10.1146/annurev-ecolsys-102710-145039
Glassner, H., Zchori-Hein, E., Compant, S., Sessitsch, A., Katzir, N., Portnoy, V., et al. (2015). Characterization of endophytic bacteria from cucurbit fruits with potential benefits to agriculture in melons (Cucumis melo L.). FEMS Microbiol. Ecol. 91:fiv074. doi: 10.1039/femsec/fiv074

Goh, C.-H., Veliz Vallejos, D. F., Nicotra, A. B., and Mathesius, U. (2013). The impact of beneficial plant-associated microbes on plant phenotypic plasticity. J. Chem. Ecol. 39, 826-839. doi: 10.1007/s10886-013-0326-8

Gopal, M., Gupta, A., and Thomas, G. V. (2013). Bespoke microbiome therapy to manage plant diseases. Front. Microbiol. 4:355. doi: 10.3389/fmicb.2013.00355

Guerrero, R., Margulis, L., and Berlanga, M. (2013). Symbiogenesis: the holobiont as a unit of evolution. Int. Microbiol. 16, 133-143.

Hamilton, C. E., Bever, J. D., Labbe, J., Yang, X., and Yin, H. (2016). Mitigating climate change through managing constructed microbial communities in agriculture. Agric. Ecosyst. Environ. 216, 304-308. doi: 10.1016/j.agee.2015.10. 006

Hanage, W. P. (2014). Microbiome science needs a healthy dose of scepticism. Nature 512, 247-248. doi: 10.1038/512247a

Haney, C. H., Samuel, B. S., Bush, J., and Ausubel, F. M. (2015). Associations with rhizosphere bacteria can confer an adaptive advantage to plants. Nat. Plants 1:15051. doi: 10.1038/NPLANTS

Hardoim, P. R., Hardoim, C. C. P., van Overbeek, L. S., and van Elsas, J. D. (2012). Dynamics of seed-borne rice endophytes on early plant growth stages. PLoS ONE 7:e30438. doi: 10.1371/journal.pone.0030438

Hardoim, P. R., van Overbeek, L. S., Berg, G., Pirtillä, A. M., Compant, S., Campisano, A., et al. (2015). The hidden world within plants: ecological and evolutionary considerations for defining functioning of microbial endophytes. Microbiol. Mol. Biol. Rev. 79, 293-320. doi: 10.1128/MMBR.00050-14

Hardoim, P. R., van Overbeek, L. S., and van Elsas, J. D. (2008). Properties of bacterial endophytes and their proposed role in plant growth. Trends Microbiol. 16, 463-471. doi: 10.1016/j.tim.2008.07.008

Hartmann, A., Schmid, M., van Tuinen, D., and Berg, G. (2009). Plant driven selection of microbes. Plant Soil 321, 235-257. doi: 10.1007/s11104-008-9814-y

Hays, S. G., Patrick, W. G., Ziesack, M., Oxman, N., and Silver, P. A. (2015). Better together: engineering and application of microbial symbiosis. Curr. Opin. Biotechnol. 36, 40-49. doi: 10.1016/j.copbio.2015.08.008

Henry, W. H. (1931). The natural microflora of the soil in relation to the foot-rot problem of wheat. Can. J. Res. 4, 69-77. doi: 10.1139/cjr31-006

Hirsch, P. R., and Mauchline, T. H. (2012). Who's who in the plant root microbiome? Nature Biotechnol. 30, 961-962. doi: 10.1038/nbt.2387

Hol, W. H., de Boer, W., Termorshuizen, A. J., Meyer, K. M., Schneider, J. H., van Dam, N. M., et al. (2010). Reduction of rare soil microbes modifies plantherbivore interactions. Ecol. Lett. 13, 292-301. doi: 10.1111/j.1461-0248.2009. 01424.x

Inouye, D. W. (2015). The next century of ecology. Science 349:565. doi: 10.1126/ science.aab1685

Johnston-Monje, D., Lundberg, D. S., Lazarovits, G., Reis, V. M., and Raizada, M. N. (2016). Bacterial populations in juvenile maize rhizospheres originate from both seed and soil. Plant Soil 405, 337-355. doi: 10.1007/s11104-0162826-0

Johnston-Monje, D., Mousa, W. K., Lazarovits, G., and Raizada, M. N. (2014). Impact of swapping soils on the endophytic bacterial communities of predomesticated, ancient and modern maize. BMC Plant Biol. 14:233. doi: 10.1186/ s12870-014-0233-3

Johnston-Monje, D., and Raizada, M. N. (2011). Conservation and diversity of seed associated endophytes in Zea across boundaries of evolution, ethnography and ecology. PLoS ONE 6:e20396. doi: 10.1371/journal.pone.0020396

Kazan, K., and Lyons, R. (2016). The link between flowering time and stress tolerance. J. Exp. Bot. 67, 47-60. doi: 10.1093/jxb/erv441

Kembel, S. W., O’Connor, T. K., Arnold, H. K., Hubbell, S. P., Wright, S. J., and Green, J. L. (2014). Relationship between phyllosphere bacterial communities and plant functional traits in a neotropical forest. Proc. Natl. Acad. Sci. U.S.A. 111, 13715-13720. doi: 10.1073/pnas.1216057111

Klaedtke, S., Jacques, M.-A., Raggi, L., Préveaux, A., Bonneau, S., Negri, V., et al. (2015). Terroir is a key driver of seed-associated microbial assemblages. Environ. Microbiol. 18, 1792-1804. doi: 10.1111/1462-2920.12977

Koberl, M., Schmidt, R., Ramadan, E. M., Bauer, R., and Berg, G. (2013). The microbiome of medicinal plants: diversity and importance for plant growth, quality and health. Front. Microbiol. 4:400. doi: 10.3389/fmicb.2013.00400 
Koonin, E. V., and Yutin, N. (2014). The dispersed archaeal eukaryome and the complex archaeal anecestor of eukaryotes. Cold Spring Harbour Perspect. Biol. 8,

Lakshmanan, V., Selvaraj, G., and Bais, H. P. (2014). Functional soil microbiome: belowground solutions to above ground problem. Plant Physiol. 166, 689-700. doi: 10.1104/pp.114.245811

Lau, J. A., and Lennon, J. T. (2011). Evolutionary ecology of plant-microbe interactions: soil microbial structure alters selection on plant traits. New Phytol. 192, 215-224. doi: 10.1111/j.1469-8137.2011.03790.x

Lau, J. A., and Lennon, J. T. (2012). Rapid responses of soil microorganisms improve plant fitness in novel environments. Proc. Natl. Acad. Sci. U.S.A. 109, 14058-14062. doi: 10.1073/pnas.1202319109

Lebeis, S. L., Paredes, S. H., Lundberg, D. S., Breakfield, N., Gehring, J., McDonald, M., et al. (2015). Salicylic acid modulates colonization of the root microbiome by specific bacterial taxa. Science 349, 860-864. doi: 10.1126/ science.aaa8764

Lesky, C., Rowhani, P., and Ramankutty, N. (2016). Influence of extreme weather disasters on global crop production. Nature 529, 84-87. doi: 10.1038/ nature 16467

Liu, S., da Cunha, A. P., Rezende, R. M., Cialic, R., Wei, Z., Bry, L., et al. (2016). The host shapes the gut microbiota via fecal microRNA. Cell Host Microbe 19, 32-43. doi: 10.1016/j.chom.2015.12.005

Lundberg, D. S., Lebeis, S. L., Paredes, S. H., Yourstone, S., Gehring, J., Malfatti, S., et al. (2012). Defining the core Arabidopsis thaliana root microbiome. Nature 488, 86-90. doi: 10.1038/nature11237

Marasco, R., Rolli, E., Ettoumi, B., Vigani, G., Mapelli, F., Borin, S., et al. (2012). A drought resistance promoting microbiome is selected by root system under desert farming. PLoS ONE 7:48479. doi: 10.1371/journal.pone.0048479

Matson, P. A., Parton, W. J., Power, A. G., and Swift, M. J. (1997). Agricultural intensification and ecosystem properties. Science 277, 504-509. doi: 10.1126/ science.277.5325.504

Mendes, R., Kruijt, M., de Bruijn, I., Dekkers, E., van der Voort, M., Schneider, J. H., et al. (2011). Deciphering the rhizosphere microbiome for disease-suppressive bacteria. Science 332, 1097-1100. doi: 10.1126/science.1203980

Mitter, B., Pfaffenbichler, N., and Sessitsch, A. (2016). Plant-microbe partnerships in 2020. Microbiol. Biotechnol 9, 635-640. doi: 10.1111/1751-7915.12382

Moran, N. A., and Sloan, D. B. (2015). The hologenome concept: helpful or hollow? PLoS Biol. 13:e1002311. doi: 10.1371/journal.pbio.1002311

Mueller, U. G., and Sachs, J. L. (2015). Engineering microbiomes to improve plant and animal health. Trends Microbiol. 23, 606-617. doi: 10.1016/j.tim.2015. 07.009

Ngumbi, E., and Kloepper, J. (2016). Bacterial-mediated drought tolerance: current and future prospects. Appl. Soil Ecol. 105, 109-125. doi: 10.1016/j.apsoil.2016. 04.009

Nogales, A., Nobre, T., Valadas, V., Ragonezi, C., Goring, M., et al. (2016). Can functional hologenomics aid tackling challenges in plant breeding? Brief. Funct. Genom. 15, 288-197. doi: 10.1093/bfgp/elv030

Oburger, E., and Schmidt, H. (2016). New methods to unravel rhizosphere processes. Trends Plant. Sci. 21, 243-255. doi: 10.1016/j.tplants.2015.12.005

Panke-Buisse, K., Lee, S., and Kao-Kniffin, J. (2016). Cultivated sub-populations of soil microbiomes retain early flowering plant trait. Microb. Ecol. doi: 10.1007/ s00248-016-0846-1 [Epub ahead of print].

Panke-Buisse, K., Poole, A. C., Goodrich, J. K., Ley, R. E., and Kao-Kniffin, J. (2014). Selection on soil microbiomes reveals reproducible trait impacts on plant functions. ISME J. 9, 980-989. doi: 10.1038/ismej.2014.196

Perez-Jaramillo, J. E., Mendes, R., and Raaijmakers, J. M. (2016). Impact of plant domestication on rhizosphere microbiome assembly and functions. Plant Mol. Biol. 90, 635-644. doi: 10.1007/s11103-015-0337-7

Pieterse, C. M. J., Jonge, R. D., and Berendsen, R. L. (2016). The soil-borne supremacy. Trends Plant Sci. 21, 171-173. doi: 10.1016/j.tplants.2016.01.018

Pikaard, C. S., and Scheid, O. M. (2014). Epigenetic regulation in plants. Cold Spring Harb. Perspect. Biol. 6:019315. doi: 10.1101/cshperspect.a

Pitzschke, A. (2016). Developmental peculiarities and seed-borne endophytes in quinoa: omnipresent, robust Bacilli contribute to plant fitness. Front. Microbiol. 7:2. doi: 10.3389/fmicb.2016.00002

Rillig, M. C., Lehmann, A., Aguilar-Trigueros, C. A., Antonovics, J., Caruso, T., Hempel, S., et al. (2016). Soil microbes and community coalescence. Pedobiologia 59, 37-40. doi: 10.1016/j.pedobi.2016.01.001
Robinson, R. J., Fraaije, B. A., Clark, I. M., Jackson, R. W., Hirsch, P. R., and Mauchline, T. H. (2016). Wheat seed embryo excision enables the creation of axenic seedlings and Koch's postulate testing of putative bacterial endophytes. Sci. Rep. 6:25581. doi: 10.1038/srep25581

Rodriguez, R. J., Henson, J., Van Volkenburgh, E., Hoy, M., Wright, L., Beckwith, F., et al. (2008). Stress tolerance in plants via habitat-adapted symbiosis. ISME J. 2, 404-416. doi: 10.1038/ismej.2007.106

Rolli, E., Marasco, R., Vigani, G., Ettoumi, B., Mapelli, F., Deangelis, M. L., et al. (2015). Improved plant resistance to drought is promoted by the root-associated microbiome as a water stress-dependent trait: root bacteria protect plants from drought. Environ. Microbiol. 17, 316-331.

Rosenberg, E., and Zilber-Rosenberg, I. (2016). Microbes drive evolution of animals and plants; the hologenome concept. MBio 7:e1395-15. doi: 10.1128/ mBio.01395-15

Santhanam, R., Luu, V. T., Weinhold, A., Goldberg, J., Oh, Y., and Baldwin, I. T. (2015). Native root-associated bacteria rescue a plant form a sudden-wilt disease that emerged during continuous cropping. Proc. Natl. Acad. Sci. U.S.A. 112, E5013-E5020. doi: 10.1073/pnas.1505765112

Sarma, B. K., Yadav, S. K., Singh, S., and Singh, H. B. (2015). Microbial consortiummediated plant defense against phytopathogens: readdressing for enhancing efficiency. Soil Biol. Biochem. 87, 25-33. doi: 10.1016/j.soilbio.2015.04.001

Schlaeppi, K., Dombrowski, N., van Themaat, E. V. L., and Schulze-Lefert, P. (2014). Quantitative divergence of the bacterial root microbiota in Arabidopsis thaliana relatives. Proc. Natl. Aacad. Sci. U.S.A. 111, 585-592. doi: 10.1073/pnas. 1321597111

Sessitsch, A., and Mitter, B. (2015). 21st century agriculture: integration of plant microbiomes for improved crop production and food security. Microb. Biotechnol. 8, 32-33. doi: 10.1111/1751-7915.12180

Shugart, E. C., and Racaniello, V. R. (2015). Scientists: engage the public. mBio 6:e1989-15. doi: 10.1128/mBio.01989-15

Slotkin, R. K. (2016). Plant epigenetics: from genotype to phenotype and back again. Genome Biol. 17:57. doi: 10.1186/s13059-016-0920-5

Spang, A., Saw, J. H., Jørgensen, S. L., Zaremba-Niedzwiedzka, K., Martijn, J., Lind, A. E., et al. (2015). Complex archaea that bridge the gap between propkaryotes and eukaryotes. Nature 521, 173-179. doi: 10.1038/nature14447

Spence, C., Alff, E., Johnson, C., Ramos, C., Donofrio, N., Sundaresan, V., et al. (2014). Natural rice rhizospheric microbes suppress rice blast infections. BMC Plant Biol. 14:130. doi: 10.1186/1471-2229-14-130

Stockwell, V. O., Johnson, K. B., Sugar, D., and Loper, J. E. (2011). Mechanistically compatible mixtures of bacterial antagonists improve biological control of fire blight of pear. Phytopathology 101, 113-123. doi: 10.1186/1471-2229-14-130

Swenson, W., Wilson, D. S., and Elias, R. (2000). Artificial ecosystem selection. Proc. Natl. Acad. Sci. U.S.A. 97, 9110-9114. doi: 10.1073/pnas.150237597

Terrazas, R. A., Giles, C., Paterson, E., Robertson-Albertyn, A., Cesco, S., Mimmo, T., et al. (2016). Plant-microbiota interactions as a driver of the mineral turnover in the rhizosphere. Adv. Appl. Microbiol. 95, 1-67. doi: 10. 1016/bs.aambs.2016.03.001

Theis, K. R., Dheilly, N. M., Klassen, J. L., Brucker, R. M., Baines, J. F., Bosch, T. C., et al. (2016). Getting the hologenome concept right: an eco-evolutionary framework for hosts and their microbiome. mSystems 1:e00028-16. doi: 10. $1101 / 038596$

Truyens, S., Weyens, N., Cuypers, A., and Vangronsveld, J. (2015). Bacterial seed endophytes: genera, vertical transmission and interaction with plants. Environ. Microbiol. Rep. 7, 40-50. doi: 10.1111/1758-2229.12181

Tsaftaris, A. S., Polidoros, A. N., Kapazoglou, A., and Kovacevic, L. N. (2008). Epigenetics and plant breeding. Plant Breed. Rev. 30, 49-177.

Turner, T. R., James, E. K., and Poole, P. S. (2013). The plant microbiome. Genome Biol. 14:209. doi: 10.1186/gb-2013-14-6-209

van der Heijden, M. G. A., and Hartmann, M. (2016). Networking in the plant microbiome. PLoS Biol. 14:e1002378. doi: 10.1371/journal.pbio.10023878.t001

van Opstal, E. J., and Bordenstein, S. R. (2015). Microbione. Rethinking heritability of the microbiome. Science 349, 1172-1173. doi: 10.1126/science.aab3958

Vandenkoornhuyse, P., Qaiser, A., Duhamel, M., Le Van Amandine, and Dufrense, A. (2015). The importance of the microbiome of the plant holobiont (Tansley Rev.). New Phytol. 206, 1196-1206. doi: 10.1111/nph.13312

Varshney, R. K., Graner, A., and Sorrells, M. E. (2005). Genomics-assisted breeding for improvement. Trends Plant Sci. 10, 621-630. doi: 10.1016/j.tplants.2005. 10.004 
Vorholt, J. A. (2012). Microbial life in the phyllosphere. Nature Rev. Microbiol. 10, 828-840. doi: 10.1038/nrmicro2910

Voss, J. D., Leon, J. C., Dhurandhar, N. V., and Robb, F. T. (2015). Pawnobiome: manipulation of the hologenome within one host generation and beyond. Front. Microbiol. 6:697. doi: 10.3389/fmicb.2015.00697

Wagner, M. R., Lundberg, D. S., Coleman-Derr, D., Tringe, S. G., Dangl, J. L., and Mitchell-Olds, T. (2014). Natural soil microbes alter flowering phenology and the intensity of selection on flowering time in a wild Arabidopsis relative. Ecol. Lett. 17, 717-726. doi: 10.1111/ele.12276

Wagner, M. R., Lundberg, D. S., Galvina del Rio, T., Tringe, S. G., Dangl, J. L., and Mitchell-Olds, T. (2016). Age, genotype and environment shape the root and leaf microbiomes of wild perennial plant. Nat. Commun. 7:12151.

Weese, D. J., Heath, K. D., Dentinger, B. T., and Lau, J. A. (2015). Long-term nitrogen addition causes the evolution of less-cooperative mutualists. Evolution 69, 631-642. doi: 10.1111/evo.12594

Wei, Z., Yang, T., Friman, V.-P., Xu, Y., Shen, Q., and Jousset, A. (2015). Trophic network architecture of root-associated bacterial communities determines pathogen invasion and plant health. Nat. Commin. 6:8413. doi: 10.1038/ ncomms 9413

Winston, M. E., Hampton-Marcell, J., Zarraonaindia, I., Owens, S. M., Moreau, C. S., Gilbert, J. A., et al. (2014). Understanding cultivar-specificity and soil determinants of the cannabis microbiome. PLoS ONE 9:e99641. doi: 10.1371/ journal.pone.0099641

Wubs, E. R. J., van der Putten, W. H., Bosch, M., and Bezemer, T. M. (2016). Soil inoculation steers restoration of terrestrial ecosystems. Nat. Plants 2:16107. doi: 10.1038/nplants.2016.107

Yeoh, Y. K., Paungfoo-Lonhienne, C., Dennis, P. G., Robinson, N., Ragan, M. A., Schmidt, S., et al. (2015). The core root microbiome of sugarcanes cultivated under varying nitrogen fertilizer application. Environ. Microbiol. 18, 13381351. doi: 10.1111/1462-2920.12925

Zachow, C., Berg, C., Müller, H., Monk, J., and Berg, G. (2016). Endemic plants harbour specific Trichoderma communities with an exceptional potential for biocontrol of phytopathogens. J. Biotechnol. 235, 162-170. doi: 10.1016/j. jbiotec.2016.03.049

Zamioudis, C., Mastranesti, P., Dhonukshe, P., Blilou, I., and Pieterse, C. M. (2013). Unraveling root developmental programs initiated by beneficial Pseudomonas spp. bacteria. Plant Physiol. 162, 304-318. doi: 10.1104/pp.112.212597

Zarraonaindia, I., Owens, S. M., Weisenhorn, P., West, K., Hampton-Marcell, J., Lax, S., et al. (2015). The soil microbiome influences grapevine -associated microbiota. mBio 6:e2527-14. doi: 10.1128/mBio.02527-14

Zelezniak, A., Andrejev, S., Ponomarova, O., Mende, R., Bork, P., and Patil, K. R. (2015). Metabolic dependencies drive species co-occurrence in diverse microbial communities. Proc. Natl. Acad. Sci. U.S.A. 112, 6449-6454. doi: 10 1073/pnas.1421834112

Zhang, T., Zhao, Y. L., Zhao, J. H., Wang, S., Jin, Y., Chen, Z. Q., et al. (2016). Cotton plants export microTNAs to inhibit virulence gene expression in a fungal pathogen. Nat. Plants 2:16153. doi: 10.1038/nplants.2016.153

Zilber-Rosenberg, I., and Rosenberg, E. (2008). Role of microorganisms in the evolution of animals and plants: the hologenome theory of evolution. FEMS Microbiol. Rev. 32, 723-735. doi: 10.1111/j.1574-6976.2008.00123.x

Zolla, G., Badri, D. V., Bakker, M. G., Manter, D., and Vivanco, J. M. (2013). Soil microbiomes vary in their ability to confer drought tolerance to Arabidopsis. Appl. Soil Ecol. 68, 1-9. doi: 10.1016/j.apsoil.2013.03.007

Conflict of Interest Statement: The authors declare that the research was conducted in the absence of any commercial or financial relationships that could be construed as a potential conflict of interest.

Copyright (c) 2016 Gopal and Gupta. This is an open-access article distributed under the terms of the Creative Commons Attribution License (CC BY). The use, distribution or reproduction in other forums is permitted, provided the original author(s) or licensor are credited and that the original publication in this journal is cited, in accordance with accepted academic practice. No use, distribution or reproduction is permitted which does not comply with these terms. 